Volume 3

Number 4 Critical Perspectives on Marketing

from Japan - Part 2

2018

\title{
Virtual Idol Hatsune Miku: Case Study of New Production/ Consumption Phenomena generated by Network Effects in Japan's Online Environment
}

\author{
Hajime Kobayashi \\ Meiji University \\ Takashi Taguchi \\ Ibaraki Christian University
}

Follow this and additional works at: https://digitalcommons.uri.edu/mgdr

Part of the Anthropology Commons, Economics Commons, Film and Media Studies Commons, Marketing Commons, Other Business Commons, and the Sociology Commons

\section{Recommended Citation}

Kobayashi, Hajime and Taguchi, Takashi (2018) "Virtual Idol Hatsune Miku: Case Study of New Production/Consumption Phenomena generated by Network Effects in Japan's Online Environment," Markets, Globalization \& Development Review: Vol. 3: No. 4, Article 3.

DOI: 10.23860/MGDR-2018-03-04-03

Available at: https://digitalcommons.uri.edu/mgdr/vol3/iss4/3

This Article is brought to you for free and open access by DigitalCommons@URI. It has been accepted for inclusion in Markets, Globalization \& Development Review by an authorized editor of DigitalCommons@URI. For more information, please contact digitalcommons-group@uri.edu. 


\section{Virtual Idol Hatsune Miku: Case Study of New Production/Consumption Phenomena generated by Network Effects in Japan's Online Environment}

\section{Cover Page Footnote}

The authors are grateful to MGDR editor Nikhilesh Dholakia and to MGDR reviewers for detailed help in the development of this article. 


\section{Markets, Globalization \& Development Review}
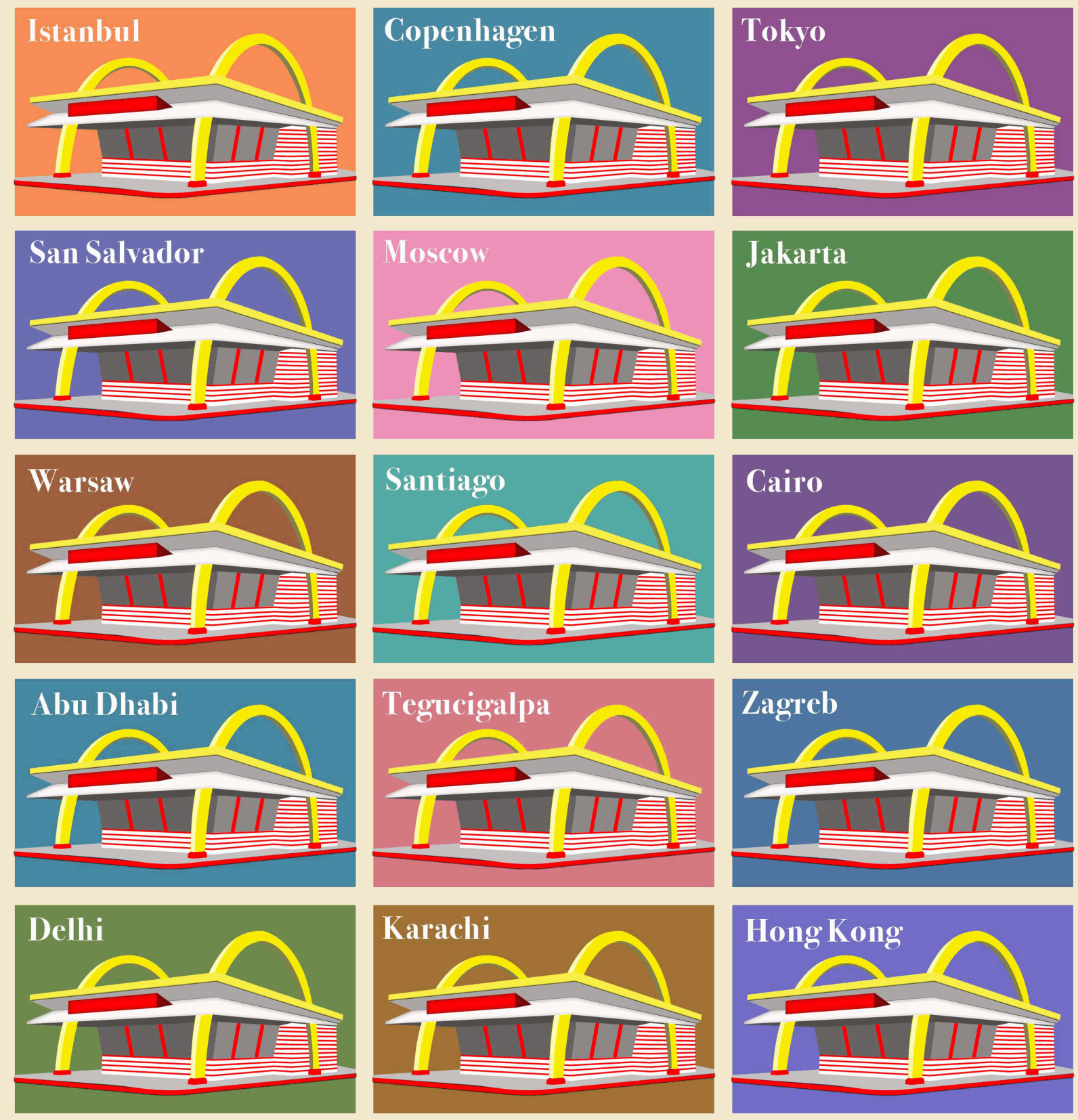

This article is available in Markets, Globalization \& Development Review: https://digitalcommons.uri.edu/mgdr/vol3/ 


\section{Virtual Idol Hatsune Miku: Case Study of New Production/Consumption Phenomena generated by Network Effects in Japan's Online Environment}

\section{Introduction}

Within the online environment, new production and consumption phenomena such as Consumer Generated Media (CGM) including video sharing websites, Social Networking Services (SNS), and User Generated Content (UGC) are gaining wider attention. A good example of this phenomenon in Japan is Hatsune Miku. This is the name of a vocaloid or a Desktop Music (DTM) software using voice synthesizer technology developed and sold by a Japanese major instrument maker Yamaha. The on-screen anthropomorphic representation of Hatsune Miku is a 16-year girl with long, turquois-colored twintails (follow the hyperlink to see images). Hatsune Miku triggered a series of production and consumption phenomena when 'she' made an appearance.

With the introduction of DTM software Hatsune Miku, a new type of user appeared: one who tries to produce his or her own original work using that software. Such active users - called Vocalo P (music producers who create songs and videos using the vocaloid software) posted their work on consumer generated media (CGM), rapidly increasing the available musical user generated content (UGC). In addition, even though the large majority of users were are not involved in the creation of content, they watched and listened to content posted on CGM. Furthermore, these (relatively passive) users offered critical comments on such content, and communicated with each other. In this paper, we will label users involved in content generation as creative users, and the users that provide active feedback while consuming these works as interactive users.

The research questions of the paper are these: How will CGM and UGC - which we characterize as new production and consumption phenomena - diffuse and spread?; What are the factors that affect such spreading and diffusion process?; and, What is the mechanism behind such spreading behavior? This paper will focus on Hatsune Miku's case - already well known as a representative case of CGM/UGC phenomena in Japan - to shed light on these questions.

The paper is organized in four substantive sections. In the next section, we explain the reason why we intentionally selected the case of Hatsune Miku as an analytical focus by relating it with the previous research findings. Many researchers have been interested in different aspects of the CGM/UGC phenomena; and most previous research has 
emphasized the phenomena of "participatory turn" - the involvement of users as co-creators and co-producers. This is the reason why we selected intentionally the case of Hatsune Miku in this paper. Next follows a section where we explain why this paper chose a single case study method, in particular a methodology called systematic combining. The characteristic of this methodology is not to rely either on the deduction method or on the induction method, but to combine the two to explore complex events. In applying this methodology, we decided, based on previous research, to adopt the 'participatory turn' concept as a provisional analytical framework.

In the section that follows, by using the archival data, we describe the longitudinal diffusion process of Hatsune Miku's story, and show how several actors' participatory moves have contributed to the Hatsune Miku phenomena. From the case analysis - employing the "participatory turn view" - we find the coexistence of two interactions that could be considered the generative mechanisms behind the Hatsune Miku phenomena.

Next we have a section where we propose that the two interaction mechanisms found in the case would mean the operation of a kind of network effect. From this effect, we try to reinterpret the Hatsune Miku case again. As a result, we point out that much of the prior research on the CGM/UGC phenomena implicitly pay attention to the network effect as a virtuous cycle - positive reinforcements across the board. We believe, however, that the network effect behind Hatsune Miku phenomenon not only works as a virtuous cycle but also, in some cases, it could also operate as a vicious cycle.

Finally, we offer some future research agenda items. Is there a turning point where the network effect can change from a virtuous cycle to a vicious cycle, and vice versa? In the contemporary online environment, could firms devise tools to prevent from switching from a virtuous cycle to a vicious cycle? Is it possible to manage the evolutionary trajectories of the CGM/UGC phenomena and their network effects?

\section{Prior Research and Purposeful Case Selection}

These days, if one searches Hatsune Miku online, then not only music created with the software, but also various Hatsune Miku related character content can be found. Many such illustrations and 3D videos can be found online. In addition, there are novels and manga produced and published with an original setting that dubs the character as "an artificially created girl that sings inside a personal computer." The appearance of this software created a "Hatsune Miku phenomenon" in Japan and in the world, which resulted in special types of production and consumption phenomena.

Many advocates see the CGM and UGC phenomenon in the 
online society as signs of a new society and a new production and consumption phenomenon emerging. To gain a deeper insight, we must see things through a perspective of "participatory turn". Participatory turn means that users not only begin to participate in production through content creation, but also engage in giving feedback and criticism directed at such generated content.

Vocalo $P$ are Hatsune Miku DTM software users that are also producers of music. These new phenomena were once pointed out by Toffler (1980) with the expressions such as "the third wave" and "prosumer (producer + consumer)". The second wave is the phenomenon in which production and consumption have been separated by the establishment of a large-scale production system by the industrial revolution. On the other hand, the third wave is the era when new archetypes emerge: those who consume goods also get involved in producing/selling of goods (and services). According to Toffler, the times are shifting from the second wave to the third wave where the active and engaged prosumer plays the leading role.

Likewise, Rifkin (2014) predicts the advent of the "zero marginal cost society" where the marginal cost of production closely approaches zero due to the spread of the three Internet technologies communications internet, energy internet, transportation/logistics internet. In a marginal cost-zero society, even without business funds, individuals can produce valuable products with little financial burden as long as they have useful talent. It is becoming possible to let everyone express their own talent without overcoming the high hurdle of huge investment in production equipment and the like. The marginal cost-zero society aids in, and boosts, the appearance and rise of the prosumer. For example, to make a debut as a professional singer in the past, a singer had to produce a lot of demonstration tapes, presented it to music producers and distributors, and had to be evaluated. It is now possible, however, to present singing voices on the websites without cost. Everyone can easily make own original products. This can also be seen as the actualization of "democratization of manufacturing". In the music and video spheres, it was fortunate that - around the time these trends were becoming evident - CGMs such as YouTube and NicoNico Douga started their services, which aided in the promotion of the 'democratization of manufacturing' in music and video spheres. The spread of CGMs such as video sharing websites created a society of zero marginal cost where anyone can produce.

The internet did not just democratize production and distribution. The spread of the internet led to consumers to have a strong interest to consume value (content) and then voice comments. They began to not just consume content, but also communicate with people through comments and thus consume communication. This type of user shares the same, commonly-viewed information or content with others and 
generates communication about such content. This is called "communication consumption". In a society of zero marginal cost, the potential and resources of users that were buried due to high barrier to entry can be utilized effectively. In addition, when creative users (Vocalo P) share their works on a UGC sharing website, then immediately interactive users get involved adding comments, which is how communication consumption becomes vibrant.

In short, these trends of modern society show signs of "participatory turn". The Hatsune Miku phenomenon in Japan is a representative case of a massive "participatory turn", a prime exemplar of "the third wave and prosumer", "zero marginal cost society", "democratization of manufacturing", "communication consumption", and related trends. The Hatsune Miku phenomenon is an extremely advanced case that cannot be thought of under normal terms. The reason for selecting such extreme case intentionally is because it shows a relatively pure example of the process generated by the phenomenon which is beneficial for research.

\section{Methodology: Systematic Combining Method for Single Case Analysis}

When studying social phenomena with complicated events intertwined, analysis using just a few select variables as a core is insufficient, so we will use the case analysis method in this paper. An advantage of performing a single case analysis is that we can provide a deeper insight (story) for the case and describe the rich context behind the case being researched.

When investigating the flow of events as a case, the preceding case becomes the context of the following case and is useful for studying the kind of links that are spawned. A study of a single case is useful in obtaining context-dependent knowledge.

In this research, we will use the abductive case study methodology as a systematic combining method for single case research studies. The systematic combining method calls for deep case research that is not superficial, and thus requires one to have a story based on experiences and a good construct.

According to Dubois and Gadde (2014), case analysis methods based on systematic combining have to rely on abductive reasoning (figuring out the cause based on the results, and creating a hypothesis). Regardless of what the research is about, the objective is to put together theory and experience. The objective at the theory level is to create a conceptual framework that can explain the development process across events based on empirical data collected; and to more efficiently probe the phenomenon compared to existing explanations.

The objective at the empirical level is to collect rich empirical data and to test, revise, and support existing conceptual framework. 
The former is called induction as it is research based on empirical facts, and the latter is called deduction as it is based on theoretical frameworks being verified. The reality of research is more than simply bifurcating research into inductive and deductive approaches; researchers in fact use some kind of mix (abduction).

Abduction is a method that goes beyond simple induction and deduction, and believes that theoretical concepts and empirical discoveries have a relationship that is not unidirectional, but has continuing mutual interaction. Thus, it means a process of creating a hypothesis by retrospective speculation regarding the generation mechanism between events. In such 'systematic combining', theoretical framework, empirical data collection, and case analysis progress and evolve simultaneously.

This method starts from a preliminary analytical framework made of articulated preconceptions that are already clear. In this paper, we will adopt the "participatory turn" and related concepts that have been discussed in prior research as the preliminary analytical framework. This preliminary analytical framework will gradually develop through empirical data collection, analysis, and interpretation.

\section{Case Description}

Hatsune Miku is a voice synthesizing DTM software released in August 2007. Table 1 provides a detailed history behind its release, and the events that followed in chronological order.

Table 1 Hatsune Miku Case History in Chronological Order

\begin{tabular}{|l|l|}
\hline Month, Year & Events \\
\hline March 2000 & $\begin{array}{l}\text { Original vocaloid technology developed by Hideki } \\
\text { Kenmochi, later dubbed Vocaloid's father, from } \\
\text { 3-year joint project of Yamaha Corporation in Japan } \\
\text { and the University of Pompeu Fabra (UPF) in } \\
\text { Barcelona, Spain. }\end{array}$ \\
\hline February 2003 & $\begin{array}{l}\text { Yamaha put Vocaloid technology to commercial use, } \\
\text { with two languages - Japanese and English }\end{array}$ \\
\hline October 2003 & $\begin{array}{l}\text { Sony Computer Entertainment released its first } \\
\text { Vocaloid game software for home game console }\end{array}$ \\
\hline Fovember 2004 & $\begin{array}{l}\text { Crypton Future Media company in Japan launched } \\
\text { 'Meiko', a female singer's DTM software, based on } \\
\text { Vocaloid technology. Version 1 had sales of 3000 } \\
\text { sets }\end{array}$ \\
\hline February 2006 & $\begin{array}{l}\text { Video sharing website "YouTube" was born in the } \\
\text { USA, subsequently acquired by Google }\end{array}$ \\
$\begin{array}{l}\text { Crypton released 'Kaito', a male singer's DTM } \\
\text { software based on Vocaloid technology - 500 sets } \\
\text { were sold }\end{array}$ \\
\hline
\end{tabular}




\begin{tabular}{|l|l|}
\hline Month, Year & Events \\
\hline December 2006 & $\begin{array}{l}\text { Dwango (founded 1997, part of Kadokawa from } \\
\text { 2014) launched Japanese video sharing service } \\
\text { 'NicoNico Douga' }\end{array}$ \\
\hline January 2007 & $\begin{array}{l}\text { Yamaha released redesigned and updated 'Vocaloid } \\
\text { 2' }\end{array}$ \\
\hline August 2007 & $\begin{array}{l}\text { Crypton launched 'Hatsune Miku' speech synthesis } \\
\text { software based on the Vocaloid 2 technology - } \\
\text { 40,000 sets sold in first year }\end{array}$ \\
\hline September & $\begin{array}{l}\text { Pixiv Inc.(founded 2005) opened Pixiv as an } \\
\text { illustrations and manga sharing website }\end{array}$ \\
\hline December 2007 & $\begin{array}{l}\text { Crypton released Kagamine Rin \& Len (which } \\
\text { packaged female vocals 'Rin' and male vocals 'Len', } \\
\text { both 14-year olds) as part of the 'Character Vocal } \\
\text { Series', following Hatsune Miku }\end{array}$ \\
\hline December 2007 & $\begin{array}{l}\text { Crypton opened Piapro creative-commons style } \\
\text { platform for users to create new blended content. To } \\
\text { legally facilitate the use of content which is the } \\
\text { copyrighted work of others, Crypton created 'Piapro } \\
\text { Character License (PCL)' }\end{array}$ \\
\hline January 2008 & $\begin{array}{l}\text { Software MikuMiku Dance released as freeware } \\
\text { (Produced by Yu Higuchi) that makes illustrations of } \\
\text { Hatsune Miku expressible by animation, Many } \\
\text { videos created by using MikuMiku Dance legally } \\
\text { posted in video sharing websites }\end{array}$ \\
\hline Launch of cartoon series 'Hatsune Miku's Everyday \\
Life!' based on Kagamine Rin \& Len as model \\
characters.
\end{tabular}




\begin{tabular}{|c|c|}
\hline Month, Year & Events \\
\hline November 2008 & $\begin{array}{l}\text { 'Yokune Ruko', an unofficial Vocaloid character, } \\
\text { appeared }\end{array}$ \\
\hline January 2009 & $\begin{array}{l}\text { Crypton released 'Mgurine Luka' as the third volume } \\
\text { of 'Character Vocal Series', following Hatsune Miku } \\
\text { and Kagamine Rin/Len }\end{array}$ \\
\hline July 2009 & $\begin{array}{l}\text { Game software 'Hatsune Miku Project Diva' released } \\
\text { by game maker Sega }\end{array}$ \\
\hline October 2009 & $\begin{array}{l}\text { 'Namine Ritu' released as an unofficial vocaloid } \\
\text { character }\end{array}$ \\
\hline May 2011 & $\begin{array}{l}\text { Toyota adopted Hatsune Miku as the main character } \\
\text { for the new Corolla commercial campaign in the } \\
\text { American market }\end{array}$ \\
\hline June 2011 & $\begin{array}{l}\text { Yamaha announced an incremental improvement, } \\
\text { 'Vocaloid version 3', with five languages - Chinese, } \\
\text { Korean, and Spanish; in addition to English and } \\
\text { Japanese }\end{array}$ \\
\hline January 2012 & $\begin{array}{l}\text { Vocalo P a.k.a. black rabbit P developed lyrics, } \\
\text { composition and arrangement of the song 'Senbon } \\
\text { Sakura' with Hatsune Miku vocals }\end{array}$ \\
\hline March 2012 & $\begin{array}{l}\text { Japanese apparel maker Cross adopted Hatsune } \\
\text { Miku as a cute character for its main brand 'earth } \\
\text { music \& ecology' }\end{array}$ \\
\hline April 2012 & $\begin{array}{l}\text { The first annual meeting, NicoNico Chokaigi, super } \\
\text { conference event for users of NicoNico Douga }\end{array}$ \\
\hline March 2013 & Novel based on song Senbon Sakura released \\
\hline March 2013 & $\begin{array}{l}\text { Virtual idol Hatsune Miku costarred in a live classical } \\
\text { concert }\end{array}$ \\
\hline November 2014 & $\begin{array}{l}\text { Yamaha announced Vocaloid version } 4 \text {, which } \\
\text { further improved expressive power and ease of use }\end{array}$ \\
\hline January 2015 & $\begin{array}{l}\text { Hatsune creator Miku Hideki Kenmochi left and } \\
\text { Katsumi Ishikawa became new Vocaloid project } \\
\text { leader }\end{array}$ \\
\hline August 2016 & $\begin{array}{l}\text { Hatsune Miku's first solo concert, Hatsune Miku } \\
\text { Symphony 2016, held. Also, Hatsune Miku appointed } \\
\text { a spokesperson for Unilever Japan's hair care brand } \\
\text { 'Lux' }\end{array}$ \\
\hline November 2017 & $\begin{array}{l}\text { Hatsune Miku Symphony } 2017 \text { held to mark the 10th } \\
\text { birthday of Virtual idol Hatsune Miku }\end{array}$ \\
\hline
\end{tabular}

Source: Authors' research

If we look into the series of events related to Hatsune Miku in terms of our provisional concept of "participatory turn," then we could see the following three points: 
1. Birth of an integral product and service system using vocaloid technology as its core: First, it is a fact that Hatsune Miku, the voice synthesizing software, had pioneering characteristics that were different from past products. Because this software incorporates vocaloid technology developed by Yamaha, even people who are not familiar with music production could easily create their own songs. Second, it is possible to proceed without a singing voice. This software generates songs produced with sounds that are built in the software. Music produced by creative users is available as a cute singing voice of a virtual idol singer-character named Hatsune Miku. In addition to selling this product as an innovative DTM software, a policy to sell such idol-characters was launched. Among users, various interactions occurred, focused on such idols topics. Understanding the Hatsune Miku phenomenon simply as a success story of a voice synthesizing software alone, however, is insufficient. It is clear from the case description that the appearance of Hatsune Miku triggered the creation of various products and services in different genres in a chain reaction, and all of that created a complex package. A fan may like a song of another fan's original character song, or illustration, or video, etc.; and cite a portion of it to create new content such as novels and manga. Then, another fan would cite that again and create more new content. Various users - that shared the worldview of Hatsune Miku clustered to stimulate a chain of creations called $\mathrm{n}^{\text {th }}$ derivative work; and that led to the birth of a package including a complex product that went beyond the boundaries of a single product or service.

2. Crypton Future Media, Inc.'s Policy of Open Copyright: One factor that promoted the birth of creative users - called Vocalo $P$ - was the policy of Crypton Future Media president Hiroyuki Ito regarding copyrights. One reason that Hatsune Miku grabbed the attention of various users in the world was Crypton Future Media, Inc.'s declaration of the "Character Guideline" followed by the "Piapro Character License (PCL)" - a form of Creative Commons licensing ('Piapro' is short form of Japanese English phrase 'peer production'). This unleashed creative urges and made it possible for anyone to legally use these characters for noncommercial reasons. According to Crypton president Ito, "Crypton is a company of 'meta-creators' who support those that are called creators. We create products and services that are necessary for creators who are our customers." Crypton Future Media, Inc. does not only promote sales of their software, but their mission has always been to cultivate creators (creative users, Vocalo P) 
through providing products and services. For that reason, Crypton Future Media, Inc. has opened a Piapro website. Whenever users post materials such as songs, movies and illustrations, they must accept the license condition that posted creative works can be cited, replicated, and blended - by other users - free of charge. As already mentioned, Crypton Future Media, Inc.'s adoption of a policy to open copyright solved the issue of copyright that all posting websites had for posted content, and allowed creative users and Vocalo $P$ folks to continue creative activities with an ease of mind. By making copyright open, even though the seller only published a few variations of Hatsune Miku illustrations, various creators, mainly amateurs, created more than a hundred thousand images for Hatsune Miku and published them on CGM. In fact, from the standpoint of Crypton Future Media, Inc., the increase of derivative works raises the value of the originals, with the result that more creative users are motivated to share their works.

3. The appearance and growth of sharing websites where users communicate interactively regarding content: One aspect that helped trigger the spread of the Hatsune Miku phenomenon was the birth of various CGM websites where users could interactively communicate about content including "YouTube" (since 2005), the Japanese video sharing website "NicoNico Douga" (since 2006), and illustrations and manga sharing and communication website "Pixiv" (since 2007). It was just coincidence, but multiple sharing websites were born around the time that Hatsune Miku was released. Through the birth of multiple sharing websites, users were given a vast space for publishing their creative content. Based on these sharing websites (so called CGM), active feedback loops emerged between creative users and interactive users. Creative users who posted songs and videos receive comments from interactive users who are viewers of the site. Creative users can refine their original works with hints and suggestions from others.

In short, Hatsune Miku, the DTM software alone did not create the CGM/UGC phenomenon, but other unintentional factors (appearance of places for interactive communication) and intentional corporate policy (free copyright use) together stimulated users to participate in the production sphere, and made them into creative users called 'Vocalo P'; and a much wider base of interactive users who could voice opinions on creative activities. In addition, these new types of users expanded the boundary of the product and service system (free creative environment, cute character setting, open copyright, various CGM, etc.) formed around vocaloid technology (see Figure 1). 
Figure 1: "Participatory Turn" Phenomenon Found in Hatsune Miku Case

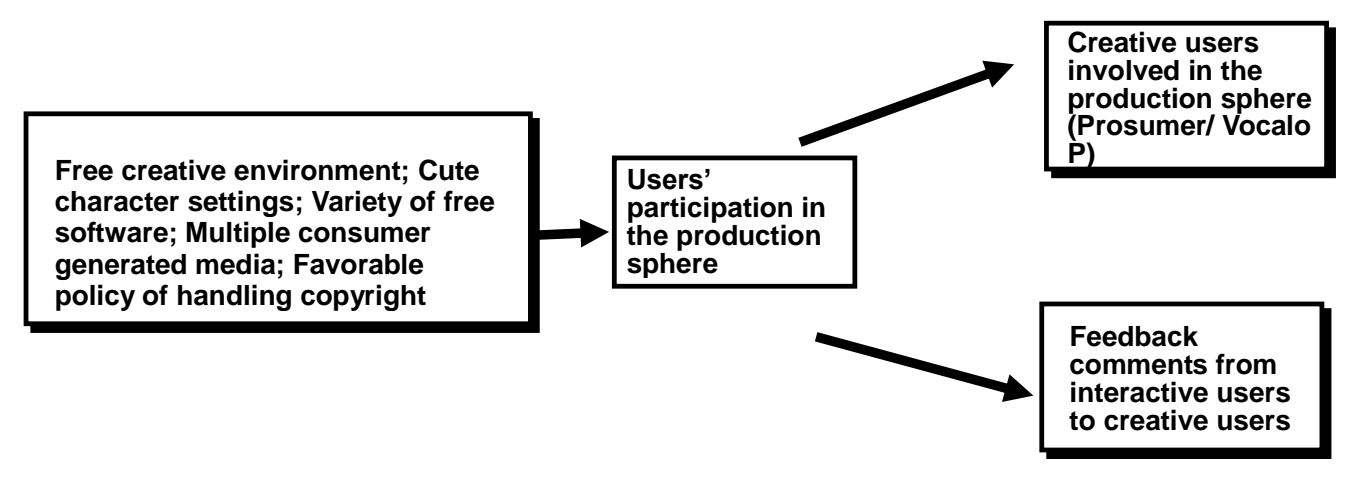

\section{Discussion: Hatsune Miku and the Innovator's Dilemma}

We have organized Hatsune Miku's case based on a tentative perspective of a participatory turn. A closer look reveals two mutual interactions behind this phenomenon. There is a mutual interaction between the complex package of products and services created around vocaloid technology and the creative users. Advancement of technology leads to creative content expansion; and the quantity and quality of the created content acts as a spur. With the arrival of the products and services package - with vocaloid technology at the core - traditional users were motivated to turn into creative users. Through the creative activities of these creative users, several content items were created, and these works added variety and expanded the product and service package even further. Even after ten years of the initial release of Hatsune Miku, the creative users continue to publish new content online, and the boundary of the complex package continues to change.

Another interaction that can be found is between the creative users that create and share content and the interactive users that view this content and return comments through sharing websites (CGM). The creative users (Vocalo $P$ ) that publish music and videos receive comments from the website viewers who are interactive users, and then the creators refine their original music and videos based on the hints they get. Immediate interaction (pseudo synchronization) is born between the creative users developing the content and the interactive users that consume content and provide comments.

From these two interactions, we can infer that there was a network effect behind the Hatsune Miku phenomenon. In other words, the first interaction is a network effect generated between the number of creative users generating works and the content of the products and service systems that support such works (hereinafter product-service system-oriented effect). The other interaction is when the number of 
creative users increase, the interactive users who watch and criticize these content increase, and the two reinforce each other. This can be thought as a network effect in a two-sided market of production and consumption (hereinafter two-sided market-oriented effect).

A new research emerges based on the case analysis: the basic mechanism that created an ecosystem of Hatsune Miku was the "two network effects" in action. A related and additional research question emerges. Network effect, in systems theory, means a positive feedback loop is in action. This signifies that if the trend moves towards one direction, then that flow will further accelerate and expand. In Hatsune Miku's case, this feedback loop is narrated as a story in which, through the quantity and quality of content acting as a spur, all of the following increase: the number of products and services that construct the ecosystem, the number of creative users that produce things, and the number of interactive users that watch and comment on the content. This is a positive feedback loop that represents a virtuous cycle (see Figure 2).

Figure 2: Two Network Effects that Created the Hatsune Miku Phenomenon

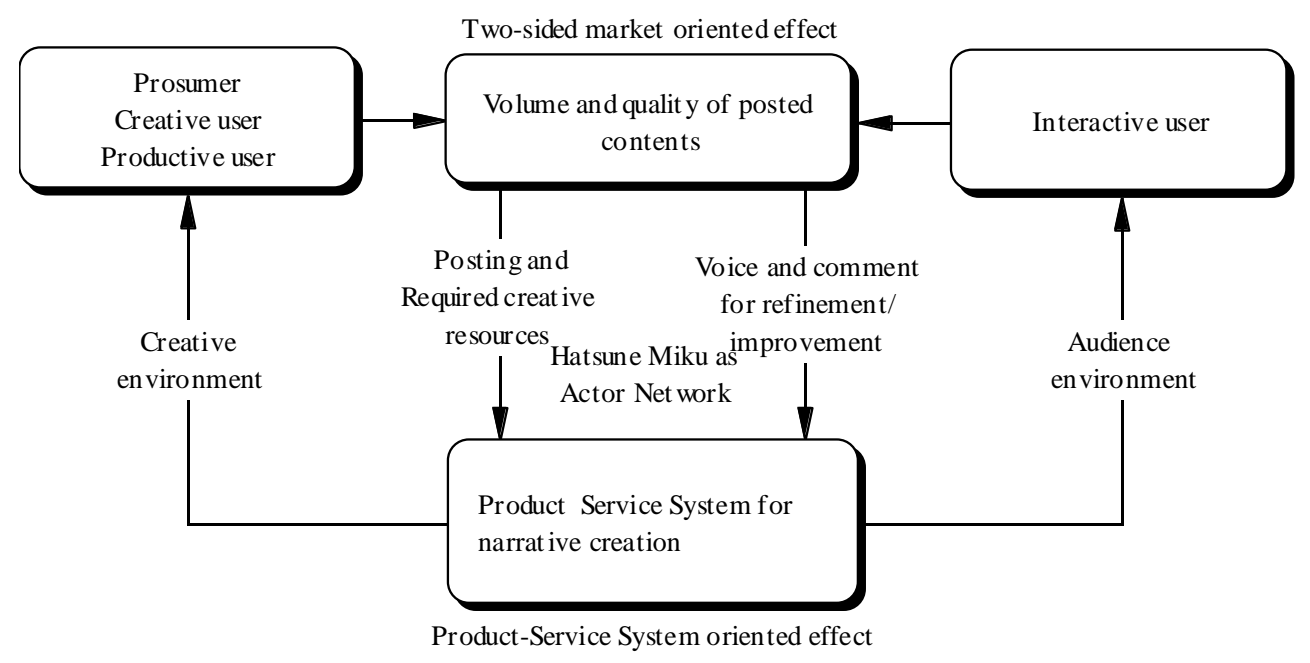

At the first stage of Hatsune Miku's spread, the fact that the content creating environment was established under a kind of free model (intentionally and unintentionally) seems to have supported the mutual interaction becoming a virtuous cycle. Copyrights usage became basically free due to the basic policy of Crypton Future Media, Inc., and the place to share copyrighted work (content) was also free. Researches in other fields have already pointed out that the adoption of the free model is effective in creating a virtuous cycle through a network effect, and the same can be said for the CGM/UGC phenomenon 
discussed in this paper.

However, the story is not as simple. The secondary research question is: can the feedback loop work as a vicious cycle instead of a virtuous cycle? A vicious cycle would mean that when one side decreases, the other side decreases, and so on. If the network effect may result in a vicious cycle instead of just a virtuous cycle, then the source of such vicious cycles can be divided in two: product service system oriented effect and two-sided market-oriented effect.

1. Vicious Cycle in a Product Service System Oriented Effect Stratification of Creative Users and Shrinking Boundary of Product Service System:

A vicious cycle here would imply the following flow: (1) The quality of product-service system becomes high-level (continued sustainable innovation), (2) the required production skills to use product service system tools becomes high, (3) creative users become stratified (separation of professional creative users and amateur creative users), (4) decreased updates and renewals of published content, (5) the boundary of product service system tends to shrink. According to an experimental study that targeted Crypton Future Media, Inc.'s posting website, "Piapro," there was a great limit found in the scope of the chain reaction of derivative works (Katano and Ishida, 2015). One reason for the derivative works to not occur is that even if there is a turn of consumers becoming creative users, the creative capabilities are not equally distributed in society, so there is a stratification of those that can become creative users, and among those that became creative users based on how well they perform. Website would show gradually the hierarchical differentiation between talented creative users and those who are not so advanced. There is a limit to participatory turn such as "democratizing production" and "birth of prosumers".

2. Vicious Cycle in a Two-sided Market Oriented Network Effect Detachment from Interest of Interactive Users:

A vicious cycle here would have the following flow: (1) Professionalization of creative users, (2) further commercialization of content, (3) interest of general interactive users deteriorates, (4) decrease in feedback (comments) from interactive users, (5) decreased content sharing and content passing its prime, (6) user community with creative users and interactive users deteriorate.

At first glance, it seems like producing high-quality content is beneficial for interactive users, but many interactive users are not just consuming high quality content (value). As the concept of 'communication consumption' indicates, these users put importance in 
sharing the same information or content with others and the communication generated therein. If many of the interactive users do not put much weight in content, but put more weight in communication, then the professionalization of creative users would likely have a negative impact on the user community.

The two vicious cycles mentioned above are linked to each other. If the creation tool provided by the product-service system becomes overwhelming, then the normal creative users will not be able to properly use them, and the creative users with higher skills start to become professionals. If only a portion of the creative users become professionals, then the interest of many interactive users drifts away, and the comment and feedback feature would not function properly, and the user community would deteriorate. In other words, when these two vicious cycles are intertwined, then a kind of "innovator's dilemma" may be born.

There is no proof that the innovator's dilemma exists for the "Hatsune Miku phenomenon" at the current moment, but there is data that shows a sign of this. Table 2 presents the data that shows change in the number of participants in the NicoNico Chokaigi live and video-streamed event since 2012, the year the event was launched.

Table 2 Changing Number of Participants in "NicoNico Chokaigi"

\begin{tabular}{|l|l|l|l|}
\hline Year & Conference & $\begin{array}{l}\text { Physical Venue } \\
\text { Visitors }\end{array}$ & $\begin{array}{l}\text { Live-streaming } \\
\text { Viewers }\end{array}$ \\
\hline 2012 & $1^{\text {st }}$ Conference & 92,384 & $3,470,766$ \\
\hline 2013 & $\begin{array}{l}2^{\text {nd }} \\
\text { Conference }\end{array}$ & 105,561 & $5,094,944$ \\
\hline 2014 & $\begin{array}{l}3^{\text {rd }} \\
\text { Conference }\end{array}$ & 124,966 & $7,864,158$ \\
\hline 2015 & $\begin{array}{l}4^{\text {th }} \\
\text { Conference }\end{array}$ & 151,116 & $7,950,495$ \\
\hline 2016 & $\begin{array}{l}5^{\text {th }} \\
\text { Conference }\end{array}$ & 152,561 & $5,548,583$ \\
\hline 2017 & $\begin{array}{l}6^{\text {th }} \\
\text { Conference }\end{array}$ & 154,601 & $5,059,967$ \\
\hline
\end{tabular}

Source: Authors' research

According to the data for the number of visitors and viewers for NicoNico Chokaigi, the increase in number of visitors has stopped happening, and there is a great decrease in the number of people watching online. Dwango Co., Ltd. - hosting NicoNico - continues to operate at a loss. The users point at the event's manners-style and the users' strong disapproval against the event's commercialization as causes. If the quality of the tool for narrative creation increases, and the number of creative users that can fully use them become limited, and 
Vocalo $\mathrm{P}$ become professionals, then these works no longer remain "hobbies" by regular people - but instead turn into "work."

Although the barrier to entry was initially lowered by having amateurs participate, suddenly, the required skillset becomes too high for amateur users to acquire easily. In addition, if the content provided by the portion of users that became professionals exceeds the expectations of ordinary interactive users, then 'communications consumption' - providing comments, feedback and having interactions - will not occur. Professional creative users would lose the support from interactive users and amateurs. This is a kind of "innovator's dilemma" found in Hatsune Miku's case.

\section{Concluding Comments}

In this paper, from the Hatsune Miku case study, we found that two mutual interactions (network effects) played an important role for UGCs diffusion process. First, the appearance of Hatsune Miku triggered a chain reaction of various products and services to be created, and that motivated users to create things, and the active content creation by the users led to expansions in the types and varieties of products and services used for creative activities. This is the first interaction that we found - we call this the product-service system-oriented effect.

Another interaction that can be found is between the creative users that create UGCs and the interactive users that view and consume such content. If a variety of UGC items are offered by creative users online, then the number of interactive users allured by such content will increase. Also, if the interactive users on the consuming side provide active comments and feedback on the content to the creative users, then the creative users' motivation will be stimulated, leading to more active creation. This is the second interaction that we found - we label this the two-sided market-oriented effect).

Based on these findings, we were able to come up with a new hypothesis that these two network effects can trigger both a virtuous cycle and a vicious cycle. The case of Hatsune Miku shows that not all amateur users have the potential to become creative users. In addition, if more and more commercial corporations participate in the product service system for creative work, then the system will have a deeper shade of commercialism. This is the contested and contentious aspect of online platforms, as other MGDR authors have alluded (Ozgun 2018).

The creative environment, ushered in by the vocaloid platforms, is not uncomfortable for all users and may be certainly a kind of utopia that everyone wants. Users however are constrained in their creativity for narrative creation within the framework of the platform. In short, it is "managed creativity". We must be cautious about seeing the participatory turn as a sign for a rosy future. 
Are there any events or causes that can trigger a switch from a virtuous cycle to a vicious cycle? Can we think of ways to suppress or circumvent the vicious cycle (the innovator's dilemma) seen in the network effect? Are there conditions to usher in true participatory democracy in online platform settings (see, e.g., Firat and Dholakia 2017)? This paper points to these as the research agenda items for the future. 


\section{References}

Azuma, Hiroki (2009), Otaku: Japan's Database Animals. Translated by J. E. Abel and Shion Kono. Minneapolis: University of Minnesota Press.

Dubois, Anna and Lars-Erik Gadde (2002), "Systematic combining: an abductive approach to case research", Journal of Business Research, 55 (7), 553-60. https://doi.org/10.1016/S0148-2963(00)00195-8

Dubois, Anna and Lars-Erik Gadde (2014),"Systematic combining”-A decade later, Journal of Business Research, 67 (6), 1277-84. https://doi.org/10.1016/i.jbusres.2013.03.036

Eisenmann, T., Geoffrey Parker and Marshall W. Van Alstyne, (2006), Strategies for Two-sided Markets, Harvard Business Review, 84 (10).

Firat, A. Fuat and Nikhilesh Dholakia (2017), "From Consumer to Construer: Travels in Human Subjectivity", Journal of Consumer Culture, 17

$504-22$. https://doi.org/10.1177/1469540515623605

Flyvbjerg, Bent (2001), Making Social Science Matter: Why Social Inquiry Fails and How It Can Succeed Again. Cambridge: Cambridge University Press.

Flyvbjerg, Bent (2006), "Five Misunderstandings about Case-Study Research," Qualitative Inquiry, 12 (2), 219-45. https://doi.org/10.1177/1077800405284363

Gauntlett, David (2007), "Media Studies 2.0," www.theory.org.uk (accessed November 15, 2017)

Gauntlett, David (2009), "Media Studies 2.0: A Response," Interactions: Studies in Communication and Culture, 1 (1), 147-57. https://doi.org/10.1386/iscc.1.1.147 1

Gauntlett, David (2011), Media Studies 2.0, and Other Battles around the Future of media Research. Kindle Edition.

Gawer, A. and Michael A. Cusumano (2002), Platform Leadership. Harvard Business School Press.

Gawer, A. and Michael A. Cusumano (2014), "Industry Platforms and Ecosystem Innovation," Journal Product Innovation Management, 31 (3), 417-33. https://doi.org/10.1111/jpim.12105

Hauser, John R. and Don Clausing (1988), "The House of Quality," Harvard Business Review, 66 (3), 63-73.

Katano, K. and Minoru Ishida (2015), "Study on the role of creative 
network by the emergent user community: value co-creation in Hatsune Miku's community" (in Japanese), Marketing Journal, 34 (4), 88-107

Ozgun, Aras (2018), "[Cntrl] + [Alt] + [Esc] ? Virtual Platforms as Spaces of Control and Contestation", Markets, Globalization \& Development Review, 3 (3), Article 1. https://doi.org/10.23860/MGDR-2018-03-03-01

Prahalad, C. K. and Venkat Ramaswamy (2004), The Future of Competition: Co-Creating Unique Value with Customers. Harvard Business School Press.

Rifkin, Jeremy (2014), The Zero Marginal Cost Society: The Internet of Things, The Collaborative Commons, and The Eclipse of Capitalism. Palgrave Macmillan.

Toffler, Alvin (1980), The Third Wave. William Morrow and Company.

Uricchio, William (2004), "Cultural Citizenship in the Age of P2P Networks," in European Culture and the Media, Bondebjerg, Ib and Peter Golding, eds. Intellect, 139-64. 